\title{
Role of insulin-like growth factor 1 in stent thrombosis under effective dual antiplatelet therapy
}

\author{
Ahmet Arif Yalcin ${ }^{1}$, Mustafa Topuz ${ }^{2}$, Ismail Biyik ${ }^{3}$, Ibrahim Faruk Akturk ${ }^{1}$, Omer Celik ${ }^{1}$, Nilgun Isıksacan ${ }^{4}$, \\ Burce Yalcın ${ }^{5}$, Ali Birant ${ }^{1}$, Fatih Uzun ${ }^{1}$ \\ ${ }^{1}$ Department of Cardiology, Mehmet Akif Ersoy Thoracic and Cardiovascular Surgery Training and Research Hospital, Istanbul, Turkey \\ ${ }^{2}$ Department of Cardiology, Adana Numune Education and Research Hospital, Adana, Turkey \\ ${ }^{3}$ Department of Cardiology, Usak State Hospital, Usak, Turkey \\ ${ }^{4}$ Department of Biochemistry, Mehmet Akif Ersoy Thoracic and Cardiovascular Surgery Training and Research Hospital, Istanbul, Turkey \\ ${ }^{5}$ Department of Microbiology, Mehmet Akif Ersoy Thoracic and Cardiovascular Surgery Training and Research Hospital, Istanbul, Turkey
}

Postep Kardiol Inter 2014; 10, 4 (38): 242-249

DOI: $10.5114 /$ pwki.2014.46765

\begin{abstract}
A bstract
Introduction: Accumulating evidence now indicates that insulin-like growth factors (IGF) and their regulatory proteins are growth promoters for arterial cells and mediators of cardiovascular diseases.

Aim: We hypothetised that IGF-1 levels could play a role in the development of stent thrombosis (ST), and aimed to investigate the associations between stent thrombosis under effective dual antiplatelet therapy and IGF-1 levels and other related factors such as disease severity and LV ejection fraction in patients undergoing coronary stent placement.

Material and methods: A total of 128 patients undergoing coronary stent implantation were included in the analysis. Seventy-seven patients experiencing ST in the first year after stent implantation were defined as the ST group. Fifty-one patients without ST at least 1 year after stent implantation were defined as the no-thrombosis (NT) group. The IGF-1 levels, Gensini scores, and other related factors were measured.

Results: The IGF-1 levels were significantly higher in the stent thrombosis group than in the no-thrombosis group (122.22 $\pm 50.61 \mathrm{ng} / \mathrm{ml}$ vs. $99.52 \pm 46.81 \mathrm{ng} / \mathrm{ml}$, respectively, $p<0.039$ ). The left ventricle ejection fraction (LVEF) values were significantly lower $(44.13 \pm 9.25 \%$ vs. $55.81 \pm 8.77 \%, p<0.0001)$ and Gensini scores were significantly higher $(63.74 \pm 26.54$ vs. $48.87 \pm 23.7$, $p<0.004)$ in the ST group than in the NT group, respectively. In the linear regression analysis, IGF-1, Gensini score, LVEF, total cholesterol, and triglycerides were found to be independent risk factors for ST.

Conclusions: This study revealed that the plasma IGF-1 levels, disease severity, were significantly higher and LVEF was lower in patients with ST. High IGF-1 levels may identify patients who are at increased risk for ST. Future trials are necessary to confirm these results.
\end{abstract}

Key words: insulin like growth factor 1 , stent thrombosis, Gensini score, left ventricle ejection fraction.

\section{Introduction}

The most feared and serious complication of coronary stent placement is stent thrombosis (ST), occurring in $0.5 \%$ to $1 \%$ of patients within 1 year [1]. ST generally presents with death or a large non-fatal myocardial infarction, and it is estimated that up to $10 \%$ of cardiac deaths after stent placement are attributable to stent thrombosis [1]. It has been reported that insulin-like growth factor 1 (IGF-1) has anti-inflammatory and anti-atherogenic properties [2]. Circulating IGF-1 is mostly secreted by the liver under the control of growth hor- mone and carries out its physiological effects via its receptors [3]. However, epidemiological studies suggest that IGF-1 is involved in the development of atherosclerosis, type 2 diabetes, and common cancers [3-5]. Because of the wide range of its biological effects and therapeutic potential in a variety of clinical disorders, IGF-1 has become the focus of research by an increasing number of investigators. Accumulating evidence now indicates that IGFs and their regulatory proteins, secreted by cells of the cardiovascular system, are growth promoters for arterial cells and mediators of cardiovascular diseases [2-5]. Ac-

\section{Corresponding author:}

Ismail Biyik MD, Assoc. Prof., Department of Cardiology, Usak State Hospital, Uşak Devlet Hastanesi Kardiyoloji Kliniği, Posta Kodu: 64100 Uşak, Turkey, phone: +90 5424173209, e-mail: ismailbiyikmd@yahoo.com

Received: 25.03.2014, accepted: 28.04.2014. 
cording to our knowledge, there is no study investigating the relations between IGF-1 and stent thrombosis.

\section{Aim}

In the present study, we hypothesised that IGF-1 levels may play a role in the development of stent thrombosis, and aimed to investigate the interactions between stent thrombosis under effective dual antiplatelet therapy (DAPT) and IGF-1 levels and other related factors such as disease severity and left ventricular (LV) ejection fraction in patients undergoing coronary stent placement.

\section{Material and methods}

\section{Study population}

This is an observational, case-controlled comparative study, which was conducted in a tertiary heart centre. One hundred and twenty-eight patients undergoing coronary stent implantation were included in the present study. Seventy-seven patients with ST diagnosed angiographically in the first year after stent implantation were defined as the ST group. Fifty-one patients who had never experienced a clinical event or angiographic thrombotic occlusion of the implanted stent at least 1 year after coronary stent placement were defined as the no-thrombosis (NT) group. The ST was classified as acute with intra-procedural or within $24 \mathrm{~h}$ of the procedure, subacute within 1 to 30 days, and late within 1 to 12 months. Clinical criteria considering ST consisted of a new episode of chest pain and/or ischaemic electrocardiographic changes and/or increased cardiac biomarkers. Angiographic criteria of ST consisted of partial or complete occlusion of the previously implanted stent with evidence of fresh thrombus. All study patients were questioned for complete medical history including the presence of hypertension, hyperlipidaemia, diabetes mellitus, alcohol use, drug use, smoking, family history of coronary artery disease (CAD), and medications used. The exclusion criteria of the study were previous coronary artery bypass grafting, low ejection fraction (<30\%), failed stenting procedures, remaining residual lesions, development of no-reflow phenomenon, complex procedures, cases of thrombosis as a procedural complication, patients not receiving dual antiplatelet therapy, renal or hepatic failure, haematological disorders, presence of chronic inflammatory or autoimmune disease, and known malignancy. All patients received dual antiplatelet therapy for 1 year after stenting. Transthoracic echocardiography was performed before discharge. The left ventricular ejection fraction (LVEF) was measured using the modified Simpson's rule [6]. Informed consent from all patients was obtained, and the study protocol was approved by the Ethics Committee of the institution in accordance with the Declaration of Helsinki and Good Clinical Practice Guidelines.

\section{Biochemical analysis}

Blood samples for biochemical parameters were collected at admission. For IGF-1 levels, blood samples were taken after 1 month from procedure because there might have been changes in IGF-1 levels at the time of acute coronary syndrome. All samples were centrifuged at $3000 \mathrm{~g}$ for $10 \mathrm{~min}$ and the serum transferred to capped tubes and stored at $-40^{\circ} \mathrm{C}$ until the analysis. All analyses were performed using Siemens Immulite IGF-I assay with solid-phase enzyme-labelled chemiluminescent immunometric assay [7]. Haemolysed, lipemic, and icteric serums were not used for analyses. Results of IGF-1 test are given as $\mathrm{ng} / \mathrm{ml}$. Venous blood samples were collected after the procedure. Troponin I levels were recorded during the hospitalisation. Glucose, creatinine level, and lipid profile were measured for all patients with a Cobas-C 501 biochemical analyser (Roche Diagnostics, Mannheim, Germany) using Roche kits. Haematological indices were evaluated from complete blood count analyses performed using a Mindray device BC-5800 (Mindray Bio-Medical Electronics Co. Ltd., Shenzhen, China) using the optical laser method. Haemoglobin, red cell distribution width, neutrophils, lymphocytes, platelets, and mean platelet volume were measured from ethylenediaminetetraacetic acid-(EDTA) based anticoagulated blood samples and assessed within 30 min of sampling. Clopidogrel and aspirin resistances were measured by impedance aggregometry method with a multiple electrode aggregometry device (Multiplate, Dynabyte Medical, Munich, Germany) [8].

\section{Coronary angiography and disease scoring}

All angiograms and stenting procedures were performed with $7 \mathrm{Fr}$ guiding catheters at a speed of 15 frames per second by experienced operators. All observations were performed by two interventional cardiologists who were blinded to the study groups. Stent thrombosis was angiographically described as a filling defect seen in multiple projections or the presence of flow-limiting thrombus with Thrombolysis In Myocardial Infarction flow grade 0,1 , or 2 in the absence of calcification [9]. The severity and extent of CAD were evaluated via Gensini score [10]. According to the Gensini score, the degree of luminal narrowing and its geographic importance are evaluated. One point is given for $1-25 \%$ of stenosis, 2 points for $26-50 \%, 4$ points for $51-75 \%, 8$ points for $76-90 \%, 16$ points for $91-99 \%$, and 32 points for $100 \%$ stenosis, and each lesion's point is multiplied by the coefficient for each vascular segment because of the functional significance (left main coronary artery $\times 5$; proximal segment of left anterior descending coronary artery $(\mathrm{LAD}) \times 2.5$; proximal segment of the circumflex artery $\times 2.5$; mid-segment of the $L A D \times 1.5$; right coronary artery, the distal segment of the LAD, posterolateral artery and the obtuse marginal artery $\times 1$; and others $\times 0.5$ ), and the sum of all gives the total score [10]. Scoring was per- 
formed and averaged by two observers who were blinded to the study groups.

\section{Statistical analysis}

Number Cruncher Statistical System (NCSS) 2007 Statistical Software (Utah, USA) package program was used for statistical analysis. In statistical analysis, descriptive statistical methods such as mean, standard deviation, median, interquartile range, frequency distributions, and independent $t$ test for comparison of groups of binary variables with normal distribution were used. The Mann-Whitney $U$ test was used for comparison of two groups with a normal distribution of variables and $\chi^{2}$ test was used for comparison of qualitative data. Logistic regression analysis was used to identify factors that may affect stent thrombosis. A $p$ value $<0.05$ was accepted to be statistically significant.

\section{Results}

The baseline clinical characteristics of patients are summarised in Table I. Both groups were similar in terms of sex, age, smoking habits, diabetes mellitus, body mass index (BMI), presence of hypertension, family history of CAD, and medications used. Of the ST patients, 27 were acute, 22 were subacute, and 28 were late ST. The left ventricle ejection fraction (LVEF) values were significantly lower (44.13 $\pm 9.25 \%$ vs. $55.81 \pm 8.77 \%$, respectively, $p<0.0001)$ and Gensini scores were significantly higher

Table I. Clinical characteristics of patients
(63.74 \pm 26.54 vs. $48.87 \pm 23.7$, respectively, $p<0.004)$ in the ST group than in the NT group. The IGF-1 levels were significantly higher in the ST group than in the NT group (122.22 $\pm 50.61 \mathrm{ng} / \mathrm{ml}$ vs. $99.52 \pm 46.81 \mathrm{ng} / \mathrm{ml}$, respectively, $p<0.039$ ) (Table I). There were no differences in both groups with regard to ASA/clopidogrel resistances and haematological parameters (Table II). In biochemical analyses, total cholesterol, triglyceride and very low density lipoprotein cholesterol levels were significantly lower and glucose levels were significantly higher in ST group than NT group patients (Table II). Procedural methods in percutaneous coronary intervention (PCI) were not different both groups (Table III). When the ST group patients were analysed with regard to time to development of the ST, only LVEF was significantly different between subgroups $(p=0.018)$ (Table IV). In the linear regression analysis, IGF-1, LVEF, total cholesterol, and triglyceride levels were found to be independent risk factors for stent thrombosis (Table V).

\section{Discussion}

The present study revealed that the plasma IGF-1 levels and Gensini scores were significantly higher and the LVEF values were significantly lower in patients with ST than in patients without ST. In biochemical analyses, total cholesterol, triglycerides and VLDL cholesterol levels were significantly lower and glucose levels were significantly higher in patients with ST than in those without

\begin{tabular}{|c|c|c|c|}
\hline Parameter & No-thrombosis (group 1$)(n=51)$ & Thrombosis (group 2) $(n=77)$ & Value of $p$ \\
\hline Age, mean \pm SD [years] & $56 \pm 9.43$ & $55.38 \pm 11.97$ & 0.755 \\
\hline \multicolumn{4}{|l|}{ Gender, $n(\%)$ : } \\
\hline Male & $38(74.51)$ & $62(80.52)$ & 0.421 \\
\hline Female & $13(25.49)$ & $15(19.48)$ & \\
\hline Diabetes mellitus, $n$ (\%) & $16(31.37)$ & $24(31.17)$ & 0.981 \\
\hline Hypertension, n (\%) & $28(54.90)$ & $37(48.05)$ & 0.448 \\
\hline Hyperlipidaemia, n (\%) & $26(50.98)$ & $31(40.26)$ & 0.232 \\
\hline \multicolumn{4}{|l|}{ History of, $n(\%)$ : } \\
\hline Alcohol use & $7(13.73)$ & $10(12.99)$ & 0.904 \\
\hline Smoking & $21(41.18)$ & $42(54.55)$ & 0.139 \\
\hline Family history of CAD & $26(50.98)$ & $39(50.65)$ & 0.971 \\
\hline Metabolic syndrome & $27(52.94)$ & $31(40.26)$ & 0.158 \\
\hline $\mathrm{BMI}$, mean $\pm \mathrm{SD}\left[\mathrm{kg} / \mathrm{m}^{2}\right]$ & $28.4 \pm 4.21$ & $27.98 \pm 3.52$ & 0.594 \\
\hline IGF-1, mean \pm SD [ng/ml] & $99.52 \pm 46.81$ & $122.22 \pm 50.61$ & 0.039 \\
\hline LVEF, mean \pm SD (\%) & $55.81 \pm 8.77$ & $44.13 \pm 9.25$ & 0.0001 \\
\hline Gensini score, mean \pm SD & $48.87 \pm 23.7$ & $63.74 \pm 26.54$ & 0.004 \\
\hline
\end{tabular}

CAD - coronary artery disease, BMI - body mass index, IGF-1 - insulin like growth factor-1, LVEF - left ventricular ejection fraction 
Table II. Biochemical and haematological characteristics of patients

\begin{tabular}{|c|c|c|c|}
\hline Parameter & No-thrombosis (group 1) $(n=51)$ & Thrombosis (group 2) $(n=77)$ & Value of $p$ \\
\hline Fasting glucose, mean $\pm \mathrm{SD}[\mathrm{mg} / \mathrm{dl}]$ & $117.77 \pm 24.56$ & $142.94 \pm 57.56$ & 0.015 \\
\hline Total cholesterol, mean \pm SD [mg/dl] & $199.94 \pm 46.82$ & $175 \pm 44$ & 0.009 \\
\hline Triglycerides, mean \pm SD [mg/dl] & $169.33 \pm 99.55$ & $120.31 \pm 53.97$ & 0.002 \\
\hline LDL-C, mean \pm SD [mg/dl] & $116.65 \pm 43.68$ & $111.11 \pm 35.06$ & 0.476 \\
\hline $\mathrm{HDL}-\mathrm{C}$, mean $\pm \mathrm{SD}[\mathrm{mg} / \mathrm{dl}]$ & $40.71 \pm 10.34$ & $44.46 \pm 48.65$ & 0.654 \\
\hline VLDL-C, mean \pm SD [mg/dl] & $35.1 \pm 20.71$ & $26.33 \pm 14.17$ & 0.016 \\
\hline $\mathrm{TSH}$, mean $\pm \mathrm{SD}[\mu / \mathrm{l}]$ & $1.62 \pm 1.92$ & $1.3 \pm 1.1$ & 0.371 \\
\hline $\mathrm{AST}$, mean $\pm \mathrm{SD}[\mathrm{U} / \mathrm{l}]$ & $50.81 \pm 101.5$ & $101.4 \pm 169.52$ & 0.152 \\
\hline Creatinine, mean \pm SD [mg/dl] & $0.91 \pm 0.22$ & $1 \pm 0.34$ & 0.147 \\
\hline $\mathrm{HGB}$, mean $\pm \mathrm{SD}[\mathrm{g} / \mathrm{dl}]$ & $13.8 \pm 2.05$ & $13.6 \pm 2.17$ & 0.636 \\
\hline WBC, mean \pm SD $[\times 10 / \mu l]$ & $9.28 \pm 2.99$ & $10.22 \pm 3.14$ & 0.141 \\
\hline RDW, mean \pm SD (\%) & $14.24 \pm 3.47$ & $13.76 \pm 1.7$ & 0.356 \\
\hline Platelet count, mean \pm SD $[\times 10 / \mu \mathrm{l}]$ & $255.84 \pm 72.94$ & $241.56 \pm 63.75$ & 0.297 \\
\hline MPV, mean $\pm S D[f l]$ & $8.16 \pm 0.85$ & $8.16 \pm 0.98$ & 0.993 \\
\hline Neutrophil count, mean \pm SD $[\times 10 / \mu l]$ & $65.47 \pm 11.12$ & $66.15 \pm 12.28$ & 0.781 \\
\hline Lymphocyte count, mean \pm SD $[\times 10 / \mu l]$ & $25.21 \pm 9.63$ & $24.59 \pm 10.55$ & 0.764 \\
\hline Neutrophil to lymphocyte ratio, mean \pm SD & $3.42 \pm 2.46$ & $3.56 \pm 2.44$ & 0.774 \\
\hline Clopidogrel resistance, mean \pm SD [AU/min] & $302.33 \pm 127.23$ & $270.34 \pm 198.4$ & 0.603 \\
\hline ASA resistance, mean $\pm \mathrm{SD}[\mathrm{AU} / \mathrm{min}]$ & $167.29 \pm 70.6$ & $153.17 \pm 83.87$ & 0.679 \\
\hline
\end{tabular}

LDL-C - low density lipoprotein cholesterol, HDL-C - high density lipoprotein cholesterol, VLDL-C - very low density lipoprotein cholesterol, TSH - thyroid stimulating hormone, AST - aspartate amino transferase, HGB - haemoglobin, WBC - white blood cell, RDW - red blood cell distribution width, MPV - mean platelet volume, ASA - acetyl salicylic acid

ST. Contrary to common belief, in this study, IGF-1 levels were found to be lower in patients without any cardiovascular events 1 year after stent implantation.
The mechanisms underlying stent thrombosis are multifactorial and include patient-related factors such as clopidogrel/acetylsalicylic acid (ASA) resistance, pro-

Table III. Procedural characteristics of patients

\begin{tabular}{|c|c|c|c|}
\hline Parameter & No-thrombosis (group 1) $(n=51)$ & Thrombosis (group 2) $(n=77)$ & Value of $p$ \\
\hline Stent diameter, mean \pm SD $[\mathrm{mm}]$ & $3.21 \pm 0.31$ & $3.1 \pm 0.4$ & 0.185 \\
\hline Stent length, mean \pm SD [mm] & $22.84 \pm 5.28$ & $22.91 \pm 7.09$ & 0.961 \\
\hline \multicolumn{4}{|l|}{ Type of stents, $n(\%)$ : } \\
\hline BMS & $46(90.20)$ & $67(87.00)$ & \multirow[t]{2}{*}{0.584} \\
\hline DES & $5(9.80)$ & $10(13.00)$ & \\
\hline \multicolumn{4}{|l|}{ Indication of stent, $n$ (\%): } \\
\hline Primary & $23(45.10)$ & $38(49.35)$ & \multirow[t]{2}{*}{0.637} \\
\hline Elective & $28(54.90)$ & $39(50.65)$ & \\
\hline \multicolumn{4}{|c|}{ Location of stent with thrombus, $n(\%)$ : } \\
\hline $\mathrm{LAD}$ & $18(58.06)$ & $43(55.84)$ & \multirow[t]{3}{*}{0.750} \\
\hline$C x$ & $4(12.90)$ & $7(9.09)$ & \\
\hline RCA & $9(29.03)$ & $27(35.06)$ & \\
\hline
\end{tabular}

$B M S$ - bare metal stent, DES - drug eluting stent, LAD - left anterior descending artery, Cx - left circumflex artery, RCA - right coronary artery 
Table IV. Clinical features according to time of stent thrombosis

\begin{tabular}{|c|c|c|c|c|}
\hline Parameter & Acute $(n=27)$ & Subacute $(n=22)$ & Late $(n=28)$ & Value of $p$ \\
\hline \multicolumn{5}{|l|}{ Gender, $n(\%)$ : } \\
\hline Male & $21(77.78)$ & $17(77.27)$ & $24(85.71)$ & 0.684 \\
\hline Female & $6(22.22)$ & $5(22.73)$ & $4(14.29)$ & \\
\hline \multicolumn{5}{|l|}{ Mortality in hospital, $n$ (\%) } \\
\hline Durviving & $25(92.59)$ & $17(77.27)$ & $25(89.29)$ & 0.257 \\
\hline Exit & $2(7.41)$ & $5(22.73)$ & $3(10.71)$ & \\
\hline Presence of diabetes mellitus, $n(\%)$ & $12(44.44)$ & $6(27.27)$ & $6(21.43)$ & 0.164 \\
\hline Presence of hypertension, $n(\%)$ & $13(48.15)$ & $12(54.55)$ & $12(42.86)$ & 0.714 \\
\hline Presence of hyperlipidaemia, $n(\%)$ & $11(40.74)$ & $7(31.82)$ & $13(46.43)$ & 0.578 \\
\hline Use of alcohol, $n$ (\%) & $3(11.11)$ & 4 (18.18) & $3(10.71)$ & 0.692 \\
\hline Smoking, $n(\%)$ & $14(51.85)$ & $13(59.09)$ & $15(53.57)$ & 0.872 \\
\hline Family history of CAD, $n(\%)$ & $14(51.85)$ & $9(40.91)$ & $16(57.14)$ & 0.516 \\
\hline Metabolic syndrome, $n$ (\%) & $9(33.33)$ & $9(40.91)$ & $13(46.43)$ & 0.611 \\
\hline \multicolumn{5}{|l|}{ Indication of first stent, $n(\%)$ : } \\
\hline Primary & $17(62.96)$ & $8(36.36)$ & $13(46.43)$ & 0.167 \\
\hline Elective & $10(37.04)$ & $14(63.64)$ & $15(53.57)$ & \\
\hline \multicolumn{5}{|l|}{ Admission, $n(\%)$ : } \\
\hline ST elevation $\mathrm{MI}$ & $24(88.89)$ & $17(77.27)$ & $23(82.14)$ & 0.550 \\
\hline Non ST MI & $3(11.11)$ & $5(22.73)$ & $5(17.86)$ & \\
\hline \multicolumn{5}{|l|}{ Location of stent with thrombus, $n(\%)$ : } \\
\hline LAD & $11(40.74)$ & $13(59.09)$ & $19(67.86)$ & 0.302 \\
\hline$C x$ & $4(14.81)$ & $2(9.09)$ & $1(3.57)$ & \\
\hline RCA & $12(44.44)$ & $7(31.82)$ & $8(28.57)$ & \\
\hline \multicolumn{5}{|l|}{ Type of stent, $n(\%)$ : } \\
\hline BMS & $24(88.89)$ & $17(77.27)$ & $26(92.86)$ & 0.249 \\
\hline DES & $3(11.11)$ & $5(22.73)$ & $2(7.14)$ & \\
\hline \multicolumn{5}{|l|}{ LVEF, $n(\%):$} \\
\hline Normal (> 55\%) & $14(51.85)$ & 4 (18.18) & $8(28.57)$ & 0.018 \\
\hline Borderline (40-55\%) & $2(7.41)$ & $10(45.45)$ & $11(39.29)$ & \\
\hline Low $(<40 \%)$ & $11(40.74)$ & 8 (36.36) & 9 (32.14) & \\
\hline
\end{tabular}

$L A D$ - left anterior descending artery, $C x$ - left circumflex artery, RCA - right coronary artery, BMS - bare metal stent, DES - drug eluting stent

cedural factors including stent choice, and postprocedural factors including type and duration of antiplatelet therapy [11]. Stent thrombosis within the first year after implantation appears to occur with similar frequency in patients with bare metal stents (BMS) or drug-eluting stents (DES), as long as the patients are treated with DAPT for the recommended duration [12]. The period of risk requiring dual antiplatelet therapy is longer with
DES due to delayed neointimal coverage [13]. The importance of the present study arises from the fact that the associations between IGF-1 levels and stent thrombosis were firstly investigated in this study excluding most important factors related to the development of stent thrombosis. In this study, all patients continued to be recommended antiplatelet therapy without interruption after stenting. There were no differences between 
Table V. Logistic regression analyses for stent thrombosis

\begin{tabular}{lcccccc} 
Parameter & $\boldsymbol{B}$ & S.E. & $\boldsymbol{P}$ & Exp(B) & \multicolumn{2}{c}{$95 \%$ CI OR } \\
\cline { 5 - 8 } & & & & & Lower & Upper \\
\hline LVEF & -0.153 & 0.03 & $<0.001$ & 0.86 & 0.80 & 0.92 \\
\hline Total cholesterol & -0.012 & 0.005 & 0.013 & 0.99 & 0.98 & 1.00 \\
\hline Triglyceride & -0.009 & 0.003 & 0.004 & 0.99 & 0.99 & 1.00 \\
\hline IGF1 & 0.010 & 0.005 & 0.043 & 1.01 & 1.00 & 1.02 \\
\hline Gensini & 0.025 & 0.009 & 0.006 & 1.03 & 1.01 & 1.04
\end{tabular}

the groups for procedural methods and clopidogrel/ASA resistance, so the effect of clopidogrel/ASA resistance and procedural and postprocedural factors for ST were similar for both groups. Also, we collected blood samples for IGF-1 levels after one month from admission because the level of IGF-1 can be affected by acute conditions such as inflammation [14]. Many studies in the past few decades have shown that acute $\mathrm{MI}$ results in a significant decrease in serum levels of total cholesterol, LDL cholesterol, and HDL cholesterol [15]. High blood glucose levels in patients admitted with AMI are common and are associated with an increased risk of death in both diabetic and non-diabetic subjects [16]. Similarly, in this study, fasting glucose was found to be higher and total cholesterol and triglycerides levels were found to be lower in patients with ST than in patients without, which is compatible with previous studies [16].

Coronary restenosis and ST remain major clinical problems after percutaneous revascularization procedures. For the last 20 years, the relationship between the IGF-1 system and cardiovascular disease has been a topic of interest. The relationships between IGF-1 levels and CAD have been pointed out in many studies. Low IGF-1 levels have been suggested as an important predictor of cardiovascular disease, even after correcting for BMI, smoking, blood cholesterol, alcohol intake, physical activity, gender, age, past history of diabetes, and family history of CAD [17]. Both traditional cardiovascular risk factors and low IGF-1 levels have been put forward as factors reducing endothelial function, as well as the progenitor cell reservoir; the latter, remaining as the main determinant of endothelial function, has also recently been shown to be directly associated with IGF-1 levels [18]. It has been asserted that another valuable protective activity of IGF-1 is the induction of prostacyclin (PGI2) synthesis in endothelial cells through the activation of phospholipase A2, PGI2 has important anti-platelet effects, and increases CAMP in vascular smooth muscle cells (VSMC), thereby inducing growth and vasodilation [18]. Moreover, IGF-1 has been put forward as increasing prothrombin time and partial thromboplastin time, without influencing circulating mediators of fibrinolysis $[19,20]$. According to the data, by promoting vasodilation and inhibiting platelet aggregation, and by protecting endothelial cells and vascular smooth muscle cells from several mechanisms of injury and death, IGF-1 does not promote atherogenesis, prevents plaque formation, and counteracts plaque destabilisation and thrombosis and its clinical correlates [21, 22].

Despite its association with many cardiovascular protective effects, is IGF-1 always a protective agent for coronary artery disease? In the present study, it was found that free/dissociable IGF-1 levels were lower in patients without ST than patients with ST. Our findings may be partly explained by several studies indicating that IGF-I is involved in local cellular events leading to restenosis after coronary angioplasty $[23,24]$. The IGF-1 is a potent stimulant of VSMC migration [25]. Different results of IGF-1 effects have been reported in the literature. Botker et al. and Lawlor et al. were unable to show any association between IGF-1 levels and coronary artery disease $[26,27]$. In the early stages of restenosis, IGF-1 levels of VSMCs from human restenotic specimens are far higher than in normal coronary VSMCs [25]. Smooth muscle cell accumulation is the key to the neointimal proliferation after angioplasty, so IGF-1 can be effective on neointimal proliferation phase after angioplasty [23-25]. The predominant IGF-1 production and action in arterial media suggests that IGF-1 has a growth-promoting effect on VSMCs after balloon injury [24]. However, it was shown that there was no IGF-I mRNA expression in the restenotic tissue obtained several months after the intervention [28]. Some cross-sectional and prospective studies suggest a positive association between IGF-1, in some cases IGF binding protein (IGFBP)-3, and atherosclerosis $[29,30]$. Others found that low IGF-1 is a predictor of risk of carotid and coronary artery disease and mortality [31-34]. However, several large prospective cohort studies failed to systematically confirm these findings $[35,36]$. Harrela et al. reported that high fasting serum IGFBP-1 is related to increased 5-year total and cardiovascular mortality in elderly men [35]. Wallander et al. also reported that high levels of IGFBP-1 at admission are associated with increased risk for cardiovascular mortality and morbidity in type 2 diabetes patients with AMI [36]. On the other hand, it has been reported that IGF-1 plays a role in potentiating platelet aggregation [37-39]. Erem et al. also reported that IGF-1 may be associated with increased fibrinogen, plasminogen activator inhibi- 
tor-1, and decreased protein S and tissue factor pathway inhibitor in acromegalic patients, which may represent a potential hypercoagulable and hypofibrinolytic state [40]. However, our results in a previous study did not show any significant association between IGF-1 levels and the development of no-reflow phenomenon in patients undergoing primary PCI for AMI [41], which may be related to the time for the measurement of IGF-1 because the level of IGF-1 may be affected by acute conditions such as inflammation [14]. Thus, IGF-1 measurement at the time of acute event may reveal uninterpretable and conflicting results.

The present study also has some limitations. It was a single-centred study and limited to the interventions of native vessels. The number of patients was small, representing a major limitation. We only measured free IGF-1 and were unable to measure IGFBPs, also representing an important limitation of the present study.

According to current reports and study results, high levels of IGF-1 may cause increased VSMC growth, migration, extracellular matrix synthesis, atherosclerotic plaque progression, neointimal proliferation [23-25], activation of platelets and coagulation system, ST, and increased mortality [35-40]. We cannot yet speculate whether IGF-1 itself would be a harmful mediator or would be helpful in determining early complications of coronary stent implantation. Measurement of IGF-1 may be useful in combination with other biomarkers. The present study suggests that high levels of IGF-1 may have a role in predicting stent restenosis and/or thrombosis at 12 months. Additional studies are also required to confirm our results and to determine whether genetically determined low IGF-1 levels or low bioactivity of IGF-1 is an important risk factor for atherosclerotic burden and ST.

\section{Conclusions}

The present study revealed that the plasma IGF-1 levels and disease severity were significantly higher and LVEF was lower in patients with ST. High IGF-1 levels may identify patients who are at increased risk for ST and would benefit from more aggressive medical therapies. Future investigations are necessary to confirm these results and to identify the precise underlying mechanisms of this relationship between IGF-1 and ST.

\section{References}

1. Holmes DR Jr, Kereiakes DJ, Garg S, et al. Stent thrombosis. J Am Coll Cardiol 2010; 56: 1357-65.

2. Higashi Y, Sukhanov S, Anwar A, et al. Aging, atherosclerosis, and IGF-1. J Gerontol A Biol Sci Med Sci 2012; 67: 626-39.

3. Burchardt P, Gozdzicka-Jozefiak A, Zurawski J, et al. Are elevated levels of IGF-1 caused by coronary arteriesoclerosis? Molecular and clinical analysis. Protein J 2010; 29: 538-44.

4. Vaessen $N$, Heutink P, Janseen JA, et al. A polymorphism in the gene for IGF-1: functional properties and risk for type 2 diabetes and myocardial infraction. Diabetes 2001; 50: 637-42.
5. Moschos SJ, Mantzoros CS. The role of IGF system in cancer: from basic to clinical studies and clinical applications. Oncology 2002; 63: 317-32.

6. American Society of Echocardiography Recommendations for Use of Echocardiography in Clinical Trials. A Report from the American Society of Echocardiography's Guidelines and Standards Committee and The Task Force on Echocardiography in Clinical Trials. J Am Soc Echocardiogr 2004; 17: 1086-119.

7. Krebs A, Wallaschofski H, Spilcke-Liss E, et al. Five commercially available insulin-like growth factor I (IGF-I) assays in comparison to the former Nichols advantage IGF-I in a growth hormone treated population. Clin Chem Lab Med 2008; 46: 1776-83.

8. Li L, Li HY, Qiao R, et al. Predictive value of antiplatelet resistance on early stent thrombosis in patients with acute coronary syndrome. Chin Med J (Engl) 2013; 126: 626-33.

9. Lemos PA, Lee CH, Degertekin M. Early outcome after sirolimus-eluting stent implantation in patients with acute coronary syndromes: insights from the Rapamycin-Eluting Stent Evaluated At Rotterdam Cardiology Hospital (RESEARCH) registry. J Am Coll Cardiol 2003; 41: 2093-9.

10. Gensini GG. A more meaningful scoring system for determining the severity of coronary heart disease. Am J Cardiol 1983; 51: 606.

11. van Werkum JW, Heestermans AA, Zomer AC, et al. Predictors of coronary stent thrombosis: the Dutch Stent Thrombosis Registry. J Am Coll Cardiol 2009; 53: 1399-409.

12. Spaulding C, Daemen J, Boersma E, et al. A pooled analysis of data comparing sirolimus-eluting stents with bare-metal stents. N Engl J Med 2007; 356: 989-97.

13. Airoldi F, Colombo A, Morici N, et al. Incidence and predictors of drug-eluting stent thrombosis during and after discontinuation of thienopyridine treatment. Circulation 2007; 116: 745.

14. Conti E, Musumeci MB, De Giusti M, et al. IGF-1 and atherothrombosis: relevance to pathophysiology and therapy. Clin Sci (Lond) 2011; 120: 377-402.

15. Barth JH, Jackson BM, Farrin AJ, et al. SPACE ROCKET Trial Group. Change in serum lipids after acute coronary syndromes: secondary analysis of SPACE ROCKET study data and a comparative literature review. Clin Chem 2010; 56: 1592-8.

16. Kosiborod M. Blood glucose and its prognostic implications in patients hospitalised with acute myocardial infarction. Diab Vasc Dis Res 2008; 5: 269-75.

17. Juul A, Scheike T, Davidsen $M$, et al. Low serum insulin-like growth factor 1 is associated with increased risk of ischemic heart disease: a population-based case-control study. Circulation 2002; 106: 939-44.

18. Empen $\mathrm{K}$, Lorbeer R, Volzke H, et al. Association of serum insulin-like growth factor I with endothelial function: results from the population-based Study of Health in Pomerania (SHIP). Eur J Endocrinol 2010; 163: 617-23.

19. Miljic D, Miljic P, Doknic M, et al. Changes in prothrombin and activated partial thromboplastin time during replacement therapy with human recombinant growth hormone in growth hormone deficient adults. Hormones 2006; 5: 187-91.

20. Padayatty SJ, Orme S, Zenobi PD, et al. The effects of insulin-like growth factor-1 on plasminogen activator inhibitor-1 synthesis and secretion: results from in vitro and in vivo studies. Thromb Haemost 1993; 70: 1009-13.

21. LaBelle EF, Tulenko TN. LDL, IGF-1, and VSMC apoptosis: linking atherogenesis to plaque rupture in vulnerable lesions. Cardiovasc Res 2004; 61: 204-5. 
22. Fernandez-Hernando C, Jozsef L, Jenkins D, et al. Absence of Akt1 reduces vascular smooth muscle cell migration and survival and induces features of plaque vulnerability and cardiac dysfunction during atherosclerosis. Arterioscl Thromb Vasc Biol 2009; 29: 2033-40.

23. Cercek B, Sharifi B, Barath P, et al. Growth factors in pathogenesis of coronary arterial restenosis. Am J Cardiol 1991; 68: 24C-33C.

24. Hansson HA, Jennische E, Skottner A. Regenerating endothelial cells express insulin-like growth factor I immunoreactivity after arterial injury. Cell Tissue Res 1987; 250: 499-505.

25. Grant MB, Wargovich TJ, Ellis EA, et al. Localization of insulin-like growth factor I and inhibition of coronary smooth muscle cell growth by somatostatin analogues in human coronary smooth muscle cells: a potential treatment for restenosis? Circulation 1994; 89: 1511-7.

26. Botker HE, Skjaerbaek C, Eriksen UH, et al. Insulin-like growth factor-I, insulin, and angina pectoris secondary to coronary atherosclerosis, vasospasm, and syndrome X. Am J Cardiol 1997. 79: 961-3.

27. Lawlor AD, Ebrahim S, Smith GD, et al. The association of insulin-like-growth factor 1 (IGF-1) with incident coronary heart disease in women: findings from the prospective British Women's Heart and Health Study. Atherosclerosis 2008; 201: 198-204.

28. Wilson VJ, Ward JPT, Burnand KG, et al. Upregulation of IGF-I and collagen I mRNA in human atherosclerotic tissue is not accompanied by changes in type 1 IGF receptor or collagen III mRNA: an in situ hybridization study. Coron Artery Dis 1996; 7: 569-72.

29. Andreassen M, Raymond I, Kistorp C, et al. IGF1 as predictor of all cause mortality and cardiovascular disease in an elderly population. Eur J Endocrinol 2009; 160: 25-31.

30. Schuler-Luttmann S, Monnig G, Enbergs A, et al. Insulin-like growth factor-binding protein-3 is associated with the presence and extent of coronary arteriosclerosis. Arterioscler Thromb Vasc Biol 2000; 20: E10-5.

31. Conti E, Andreotti F, Sestito A, et al. Reduced levels of insulin-like growth factor-1 in patients with angina pectoris, positive exercise stress test, and angiographically normal epicardial coronary arteries. Am J Cardiol 2002; 89: 973-5.

32. Ruidavets JB, Luc G, Machez E, et al. Effects of insulin-like growth factor 1 in preventing acute coronary syndromes: the PRIME study. Atherosclerosis 2011; 218: 464-9.

33. Brugts MP, van den Beld AW, Hofland LJ, et al. Low circulating insulin-like growth factor I bioactivity in elderly men is associated with increased mortality. J Clin Endocrinol Metab 2008; 93: 2515-22.

34. Janssen JA, Stolk RP, Pols HA, et al. Serum total IGF-I, free IGF-I, and IGFB-1 levels in an elderly population: relation to cardiovascular risk factors and disease. Arterioscler Thromb Vasc Biol 1998; 18: 277-82.

35. Harrela M, Qiao Q, Koistinen R, et al. High serum insulin-like growth factor binding protein-1 is associated with increased cardiovascular mortality in elderly men. Horm Metab Res 2002; 34: 144-9.

36. Wallander M, Norhammar A, Malmberg K, et al. IGF binding protein 1 predicts cardiovascular morbidity and mortality in patients with acute myocardial infarction and type 2 diabetes. Diabetes Care 2007; 30: 2343-8.

37. Kim S, Garcia A, Jackson SP, et al. Insulin-like growth factor-1 regulates platelet activation through $\mathrm{PI3}$-Kalpha isoform. Blood 2007; 110: 4206-13
38. Hers I. Insulin-like growth factor-1 potentiates platelet activation via the IRS/PI3Kalpha pathway. Blood 2007; 110: 4243-52.

39. Stolla MC, Li D, Lu L, et al. Enhanced platelet activity and thrombosis in a murine model of type I diabetes are partially insulin-like growth factor 1-dependent and phosphoinositide 3-kinase-dependent. J Thromb Haemost 2013; 11: 919-29.

40. Erem C, Nuhoglu I, Kocak M, et al. Blood coagulation and fibrinolysis in patients with acromegaly: increased plasminogen activator inhibitor-1 (PAI-1), decreased tissue factor pathway inhibitor (TFPI), and an inverse correlation between growth hormone and TFPI. Endocrine 2008; 33: 270-6.

41. Akturk IF, Yalcin AA, Biyik I, et al. The role of insulin-like growth factor-1 in development of coronary no-reflow and severity of coronary artery disease in patients with acute myocardial infarction. Postep Kardiol Inter 2014; 10: 12-7. 